\title{
O corpo na cidade: gênero, cultura material e imagem pública
}

Bodies in the city: gender, material culture, and portraiture

\author{
Solange Ferraz de Lima \\ Vânia Carneiro de Carvalho
}

No final do século XIX, na cidade de São Paulo, a ação coordenada de diferentes formas de representação do indivíduo no espaço público teve papel relevante na implantação de um novo modo de vida urbano. As novas noções e comportamentos na cidade estiveram pautados na exposição pública do corpo mobilizado por práticas laicas, regradas não apenas pela ação governamental, mas por

\footnotetext{
Este artigo articula as questões de ornamentação com ferro, discutidas em parte no primeiro capítulo de Lima (2002), com a pesquisa sobre o retrato de estúdio, publicada em Carvalho \& Lima (2005).

Solange Ferraz de Lima é docente do Museu Paulista da Universidade de São Paulo e doutora em História Social pelo Departamento de História da Faculdade de Filosofia, Letras e Ciências Humanas da Universidade de São Paulo, São Paulo, Brasil (sflima@usp.br).

Vânia Carneiro de Carvalho é docente do Museu Paulista da Universidade de São Paulo e doutora em História Social pelo Departamento de História da Faculdade de Filosofia, Letras e Ciências Humanas da Universidade de São Paulo, São Paulo, Brasil (vcarvalh@usp.br).

Artigo recebido em 6 de setembro de 2011 e aprovado para publicação em 12 de setembro de 2011.
} 


\section{Solange Ferraz de Lima e Vânia Carneiro de Carvalho}

sistemas materiais e visuais de ornamentação que orientaram esse novo modo de viver o espaço público na cidade. As experiências com a instalação de mobiliários urbanos, a difusão maciça de fotografias e cartões postais da cidade, a produção de retratos em estúdio e o uso de objetos de decoração doméstica atuaram como vetores para novas posturas corporais e gestualidades que fizeram parte de uma etiqueta de comportamento em público, como sentar-se, manter-se em pé, e em que apoiar-se. Para as regras que controlavam o movimento corporal no espaço público, o mobiliário de ferro (e suas representações gráficas) revelou-se um contra-ator, como o é a barra de exercícios para ginastas e bailarinos.

\section{O ferro na cidade: cercamentos}

Foram as exposições universais que disseminaram o uso do ferro como portador de dupla função - estrutural e decorativa. Em 1851, o Palácio de Cristal, construído em Londres para abrigar a primeira Exposição Universal, e mais tarde a Torre Eiffel, erguida em 1889, por ocasião da Exposição Universal de Paris, consagraram o ferro como signo da modernidade urbana. Ambos conjugavam beleza ornamental e tecnologia construtiva. Balcões, gradis, portões, bancos, luminárias, coretos, mictórios, guaritas e quiosques produzidos em ferro fundido ou batido atuaram na transformação da cidade em paisagem urbana, esta também uma invenção moderna que o século XIX nos legou. ${ }^{1}$ Colocado a serviço de exigências de caráter disciplinar, o ferro contribuiu para materializar novas práticas associadas ao convívio nos espaços públicos abertos. Agiu como organizador visual do mobiliário urbano e da arquitetura, auxiliando na demarcação dos espaços públicos e privados. Especificamente, o ornamento em ferro forneceu o vocabulário visual para indicar funções e hierarquias e para criar ressonâncias com outros objetos ornamentados da mesma forma, logrando, com isso, suscitar sentidos e induzir ações sociais.

A partir da década de 1870, a administração pública regulou o uso de parques, jardins, praças e largos da cidade de São Paulo por meio dos cercamentos de ferro, que interferiram na fruição visual, na locomoção, nos horários de frequência e na triagem de seus visitantes. $\mathrm{O}$ jardim da praça João Mendes recebeu grades em 1879, o Jardim da Luz, em 1881, o largo de São Bento em 1887, e o jardim do Pátio do Colégio em 1896 (Bruno, 1984: 996-999).

De todos os jardins e praças da capital paulista, o Jardim da Luz foi o que obteve mais atenção das sucessivas administrações públicas. Sua trajetória permite entender modismos e estilos no paisagismo, além de aspectos da sociabilidade em espaços públicos que, em São Paulo, tomaram impulso no último quartel do século XIX. As reformas mais efetivas começaram na administração de 
João Teodoro (1870), com melhorias no tipo de vegetação e com a construção de um mirante, conhecido como Canudo do Teodoro. Em fins do século XIX e já na década de 1900, durante a administração de Antônio da Silva Prado, o desenho do jardim sofreu alterações e aproximou-se do modelo inglês de passeio - com ênfase nas alamedas e caminhos, fugindo do excessivo geometrismo, próprio dos jardins franceses. Entre as melhorias relatadas periodicamente em notas na imprensa destacam-se a colocação de mobiliário urbano e a preferência pelo ferro nas estruturas e ornamentação. No início da década de 1880, o Jardim recebeu 166 metros de gradis e portão, ambos confeccionados na Fábrica de Ferro Ipanema (Bruno, 1981:999). Com a apresentação musical da Banda da Força Policial da São Paulo, em 1902 foi inaugurado o coreto, projeto de Maximiliano Hehl. ${ }^{2}$ É nesse período que o Jardim da Luz assiste ao incremento de seu uso como passeio público, tal como ocorria na Europa. As festas e os concertos musicais contavam, inclusive, com a presença do próprio prefeito e de sua família. As apresentações da Banda da Força Militar às quintas-feiras e aos domingos eram concorridas e frequentadas pelas famílias abastadas da sociedade paulistana.

Lugares para ver e ser visto, os jardins públicos funcionavam também como o palco de jogos sociais, pois o flerte, o namoro e os arranjos matrimoniais começavam a se delinear no espaço público, antes de serem solenizados na intimidade do espaço privado. Na revista $A$ Cigarra $^{3}$ encontram-se inúmeras matérias e "instantâneos" de eventos ocorridos não só no Jardim da Luz, mas também em outros parques e praças, como o Jardim da Aclimação, os prados da Mooca, o Trianon, na avenida Paulista. Na década de 1910, quermesses e festas beneficentes atraíam o público jovem e as notícias sobre tais eventos vinham acompanhadas de outras, típicas de colunas sociais, onde se comentava a beleza ou o interesse de jovens uns pelos outros (A Cigarra, n. 29, out. 1915).

Como dispositivos de controle do uso dos espaços públicos abertos, as grades garantiam que os passeios públicos ou jardins fossem reservados aos privilegiados ou à "gente de botina, de cartola, de gravata, de chapéu de sol” como já observado por Gilberto Freyre (1951:16). Estes cercamentos de ferro foram uma característica marcante dos jardins criados ou remodelados no século XIX. Inúmeras descrições de cronistas e viajantes citam os gradis e portões, típicos dos "embelezamentos" da cidade do século XIX. No trecho de Paulo Cursino de Moura, a referência ao gigantismo dos portões e das grades no largo de São Bento, bem como aos horários de abertura e fechamento explicitam as funções de proteção e controle que se esperava lograr com os cercamentos:

Como todo jardim público de outrora, o que existiu no Largo de S. Bento, em 1887, era gradeado. Uma grade de ferro, alta, bor- 
dada, em redor do perímetro ajardinado, e, em duas faces, entrada e saí$\mathrm{da}$, os portões gigantescos e emperrados, abrindo-se ao aquecer do sol e fechando-se às Aves-Marias (Moura, 1943:43).

A partir de 1881, o Pátio do Colégio começou a sofrer reformulações que culminaram, em 1896, com a constituição de um jardim com características de uma miniatura de passeio público. O resultado mais imediato do tratamento paisagístico foi o disciplinamento das práticas que o pátio, agora renomeado largo do Palácio, abrigava - a missa, os concertos musicais, os exercícios militares, os comícios e os festejos.

A banda da Força Pública (...) dava dois concertos por semana, às quintas-feiras no jardim do Palácio... O Pátio do Colégio constituía o Jardim do Palácio, cercado de grades com dois portões abertos. No lugar de onde parte o viaduto Boa Vista, ficava o coreto, em forma de concha acústica voltada para o jardim... Terminado o jantar, às cinco, as famílias dos bairros vinham vindo. Sentavam nos bancos do jardim. Os vadios eram escorraçados e ficavam para o lado de fora das grades (Americano, 1957: 198).

As "grades com dois portões" participaram da transformação do "Pátio do Colégio" em "Jardim do Palácio". Tal transformação representou uma nova maneira de fruição do espaço público aberto. Intrínsecos a essa transformação estavam os dispositivos estéticos que disciplinaram as novas práticas de convívio social - os músicos no coreto, as famílias que chegavam e se sentavam onde antes se sentaram os vadios que as grades se encarregaram de manter do "lado de fora" (Figura 1).

Para caracterizar a grade de ferro do jardim do largo de São Bento, Paulo Cursino de Moura recorre ao termo "bordado" e Jorge Americano chama a atenção para a "forma de concha" do coreto do Jardim do Palácio. De modo geral, para balcões, portões e gradis de ferro fundido os motivos e padrões ornamentais aplicados eram aqueles emprestados de repertórios franceses do século XVIII, desenvolvidos para o ferro forjado, ou de repertórios de arquitetos de expressão como Robert Adam (Costa, 1994:174). Wasth Rodrigues (1975:3) observa que os primitivos balcões de São Paulo assemelhavam-se àqueles de influência portuguesa encontrados na Bahia e em Pernambuco - varões verticais, com elemento ornamental apenas nas extremidades, sucedidos por balcões apresentando padrões barrocos de ornamentação. 


\section{Figura 1}

Palácio do Governo, 1891. Fotografia impressa. Acervo Museu Paulista da Universidade de São Paulo.

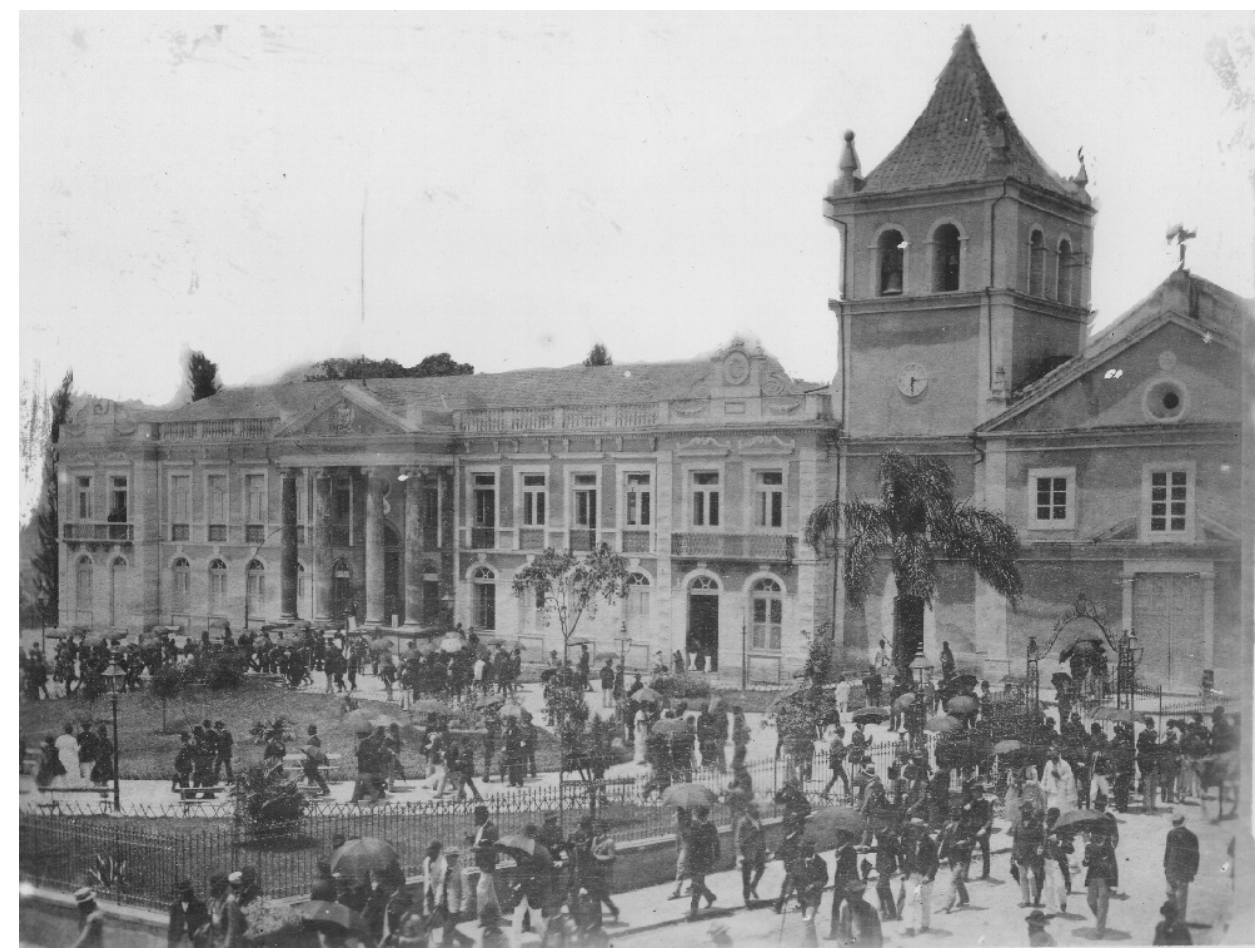

O principal propagador desses modelos europeus em São Paulo foi o Liceu de Artes e Ofícios. Ana Maria Belluzzo (1988: 279-284) descreve o processo de execução das volutas, a montagem dos painéis de grades e balcões, e chama a atenção para a convivência de estágios técnicos e para a variedade de motivos recuperados de repertórios que reuniam tipologias desde a antiguidade, privilegiando-se os ornamentos vegetais - hibridismo que foi uma das marcas próprias do período e das obras ecléticas (Belluzzo, 1988: 281). As volutas em "C" e em "S" constituíram o mais popular dos motivos ornamentais, apropriadas por diferentes estilos e em diferentes suportes.

Da arquitetura, a voluta migrou para o mobiliário e disseminou-se ao longo do século XVIII nos artefatos de ferro forjado. A voluta em "C", introduzida na Europa como legado do Império Romano, passou a ser conhecida como românica e desde então logrou absoluta permanência, graças à sua versatilidade 
para combinações (Hamlin, 1966: 27; Nicolletti, 1978: 166). Em São Paulo, a voluta românica foi recorrente e ganhou popularidade devido à presença italiana do final do século XIX. É possível ainda hoje encontrar casas populares construídas nas primeiras décadas do século XX com portões e gradis de ferro forjado decorados com a voluta, sobretudo nos bairros de forte influência italiana, como o Cambuci, Brás, Mooca e Bom Retiro.

\section{Figura 2}

Retrato de Militão Augusto de Azevedo, 1862-1885. Carte de visite em albumina sem título, autor desconhecido (auto-retrato?), Photographia Carneiro \& Gaspar. Nota-se o trabalho gráfico de emolduramento presente no cartão que recebe o papel albuminado. Acervo do Museu Paulista da Universidade de São Paulo.

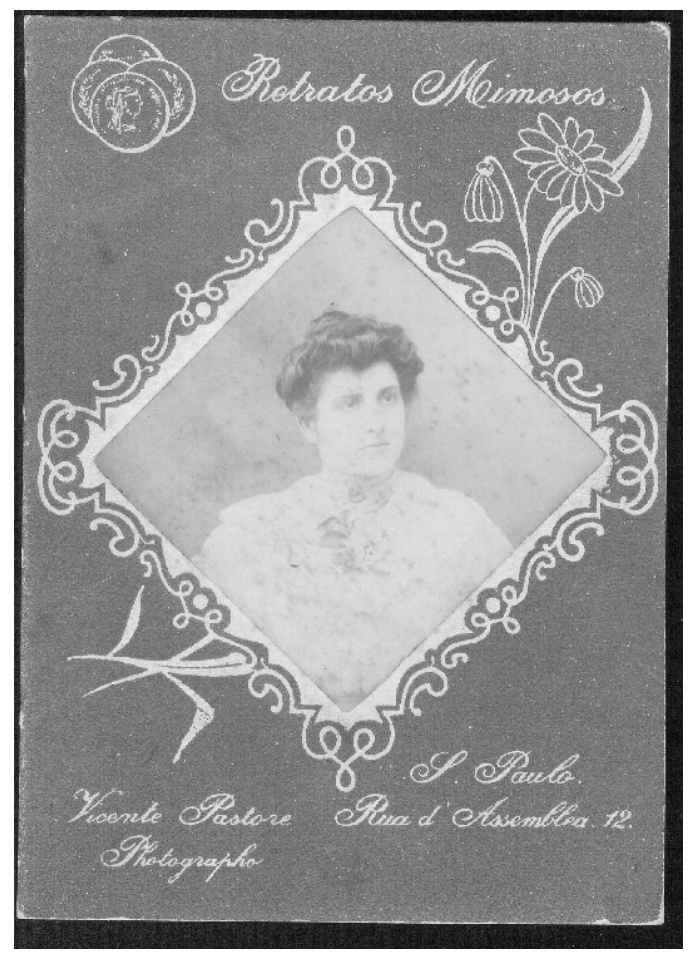

O ornamento em ferro e as performances sociais por ele agenciadas mantiveram relações com outros sistemas decorativos como o das artes gráficas ${ }^{4}$ (Figura 2), dos cenários para retratos fotográficos e dos objetos de decoração de interiores residenciais, inclusive aqueles artesanais como a renda e o bordado. 
As ressonâncias formais garantiram uma comunicação efetiva entre conjuntos de práticas sociais aparentemente distantes, como as que se desenvolveram nos espaços públicos e nos privados, ou aquelas que disseram respeito a homens ou a mulheres. As afinidades formais estavam claras até mesmo no vocabulário comum utilizado, como o uso recorrente de termos como "rendilhado" $\mathrm{e}$ "bordado". A estrutura vazada, propiciando um jogo formal de cheios e vazios, e as funções de arremate, finalização e emolduramento que o ferro ornamental veio a cumprir no contexto da aparência da cidade, assemelham-se àquelas desempenhadas pelas rendas e bordados nos objetos domésticos. Embora não tenha encaminhado a análise nesse sentido, esta função não passou despercebida a Belluzzo:

A grade de ferro, parede rendilhada, não só apareceu em resposta a determinadas exigências da arquitetura, como atendeu os reclamos do gosto e do decoro, da mesma maneira que as golas de renda rematam os vestidos na época (Belluzzo, 1988: 275).

Estrutura capaz de garantir a legibilidade dos espaços externos, a moldura e o arremate do ferro mimetizavam diversas formas de organização dos objetos na decoração de interiores residenciais tal como praticada no Brasil, no século XIX. Os bordados e as rendas de bilro e agulha (sendo o tricô e o crochê os mais populares) funcionavam como acabamentos de toalhas de mesa, de cama e de banho. Estes, por sua vez, ornamentavam móveis, escondiam os objetos de trabalho e os objetos mecânicos (indesejáveis nos ambientes sociais da casa), revestiam objetos disfarçando sua funcionalidade explícita - como era o caso de inúmeros porta-coisas -, constituíam, enfim, formas de organização visual em ambientes saturados de objetos e atuavam, assim como no caso dos gradis e dos jardins, ocultando, valorizando, delimitando, recortando, enfatizando, hierarquizando (cf. Carvalho, 2008). E oportuno lembrar o que Walter Benjamin, em sua obra Passagens (apud Buck-Morss, 1990: 295), atento às formas específicas de exposição do mundo material no século XIX, afirma:

It is scarcely possible to discover a thing for which the nineteenth century did not invent casings: for pocket watches, slippers, egg cups, thermometers, playing cards - and in lieu of casing, then covers, carpets runners, linings and slipcovers.

Para Benjamin, a ornamentação podia ser entendida como um enorme porta-cidade, e as novas aplicações estruturais do ferro mantinham-se camufladas sob ornamentos lineares e vazados, presentes nos inúmeros balcões e gradis espalhados por Paris e na própria Torre Eiffel. 
Aplicado ao mobiliário urbano, o ferro ornamental ajudou a dar contornos às ações corporais que passaram a se desenvolver ou ganhar visibilidade nos espaços públicos abertos. Para além da ação disciplinar, o ferro ornamental nos parques e jardins serviu para dirigir cenograficamente a atuação dos citadinos na paisagem urbana moderna.

\section{O corpo na cidade: enquadramentos}

O surgimento do mobiliário urbano indicava novas necessidades de conforto para o desempenho de atividades sociais laicas que se tornavam cada vez mais públicas: os esportes, as festas e os piqueniques ao ar livre, as comemorações cívicas, os concertos musicais. $\mathrm{E}$ foi graças à imagem fotográfica, circulada em escala de massa, que o transeunte anônimo se tornou o modelo, visualmente apreensível, do cidadão genérico, fruidor dos jardins, transeunte das ruas, passageiro do transporte coletivo. A fotografia, como parte integrante das representações que sustentaram condutas sociais, depurou o que se esperava do corpo na composição da paisagem dos espaços públicos abertos, como se pode depreender da análise dos registros fotográficos do Jardim da Luz e da praça da República, predominantemente de autoria de Guillherme Gaensly ${ }^{5}$ e publicados em álbuns e cartões postais, bem como de reportagens ilustradas de revistas de variedades da década de 1910.

Tais noções, no entanto, começaram a ser formadas cinquenta anos antes, dentro dos estúdios fotográficos. O retrato produzido em estúdio ao longo do século XIX integra as práticas sociais ${ }^{6}$ responsáveis pela constituição da noção de público na nova cidade que se apresentava. Longe da espontaneidade dos instantâneos, que tardarão a ganhar os ateliês dos fotógrafos profissionais, o retrato é uma síntese da realidade indiciária inescapável e da imagem ideal e pública ambicionada pelo indivíduo. Por conta de seu sentido conotativo o retrato está longe de ser realista. Ao contrário, a retratística está sujeita ao jogo social, materializando as regras e a etiqueta do viver urbano (Brilliant, 1991; Pointon, 1993; Orvell, 1989). O circuito dos elementos visuais do retrato fotográfico não se restringiu ao espaço do estúdio, mas se integrou a uma lógica maior, determinada por regimes visuais que organizaram os sentidos específicos da distinção social e de gênero na cultura da cidade.

Observe-se como as formas de tratamento do corpo no ateliê fotográfico e na paisagem urbana possuem intersecções importantes. Tome-se como exemplo as fotografias da Praça da República. Inaugurada em 1905, a praça contava com um desenho que dispensava gradis e portões. O ferro ornamental, no entanto, não deixara de ocupar lugar de destaque nos bancos, nas luminárias e nas ba- 
laustradas das pontes que ligavam os caminhos tortuosos sobre o lago artificial. Nos cartões postais referentes à praça, as tomadas parciais suprimiram o seu entorno, enfatizando os elementos da natureza - a água e a arborização. No entanto, quando os usuários da praça figuram na imagem, o ferro ornamental substitui os elementos naturais na estruturação da pose. As pontes que cortam o lago são privilegiadas em tomadas que dispõem os modelos em plano médio, com os gradis sobrepondo-se aos corpos dos retratados ou servindo de apoio a eles. Como resultado, tem-se em destaque tronco e cabeça, em composição visualmente semelhante ao retrato de meio-corpo ou ao enquadramento que o balcão das sacadas de residências promove aos seus moradores quando espectadores da rua (Figura $3)$.

\section{Figura 3}

S. Paulo. Jardim da Praça da República. Ca. 1910. Cartão postal. Acervo particular.

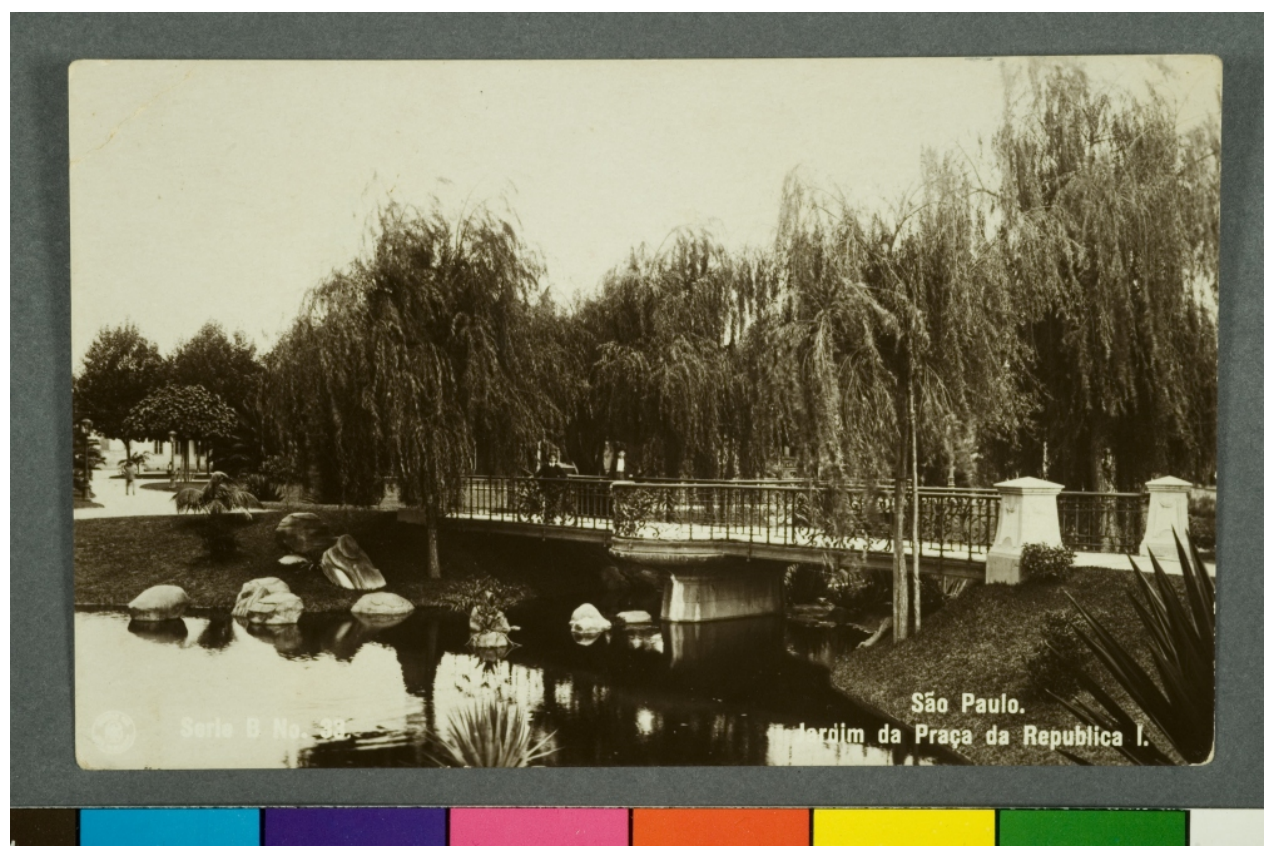

O estúdio fotográfico proporcionou para a maioria dos retratados experiências muito parecidas às que estes vivenciaram ao transitar pelos espaços em transformação na cidade. Assim como o ferro emoldurava, enquadrava e orna- 


\section{Solange Ferraz de Lima e Vânia Carneiro de Carvalho}

mentava a figura no espaço público, o retratado podia se observar nos recortes próprios da fotografia - corpo inteiro, meio corpo, busto. Corpos cercados por um ambiente decorado com os símbolos do bom gosto e refinamento burgueses, onde aos objetos próprios aos espaços domésticos somaram-se colunas e balaustradas, transpostas do ambiente urbano para dotar as poses de dignidade pública.

Na segunda metade do século XIX, era efetivo o poder da ornamentação arquitetônica em distinguir edifícios no tecido urbano e, mais do que isso, em explicitar o poder econômico dos proprietários de residências luxuosas e ornamentadas nos preceitos do que se considerava de bom gosto neste período, ou seja, o neoclássico. São Paulo, que vive o seu primeiro surto de crescimento e afluência de capitais, começa a ter suas feições alteradas por loteamentos e residências de alto padrão. Para essas residências, a ornamentação das fachadas baseava-se em colunatas, frisos e vasos, emoldurando janelas e portas e criando, visualmente, enquadramentos semelhantes àqueles do retrato fotográfico. Na cultura visual de uma sociedade emergente como a que tratamos, a visibilidade pública do indivíduo se faz representar por elementos arquitetônicos presentes nas fachadas das residências burguesas, transmutados em cenografia de estúdio. Não é por acaso que, em $70 \%$ das poses eretas de corpo inteiro, o pedestal, a coluna e a balaustrada (elementos presentes nas fachadas residenciais) ou, ainda, a pedra cenográfica (elemento presente nos parques e passeios públicos) compõem o cenário (Figuras 4 e 5).

Os retratos aproximavam-se formalmente do modo de inserção do corpo na cidade burguesa também pelo modo como eram apresentados - as albuminas eram coladas em cartões de alta gramatura, "bordados" por filetes que contornavam a figura humana. Cartões que eram, por sua vez, colocados em álbuns com janelas adornadas, porta-retratos, ou, no caso dos daguerreótipos, ferrótipos e ambrótipos, em caixas que serviam como um passe-partout ou um "porta-coisa".

Voltando às fotografias da praça da República, observa-se que a escolha de ângulos que enquadram o corpo feminino por meio da sobreposição do ferro ornamental sinaliza a necessidade de decoro na exposição pública do corpo feminino (Figura 3). John Tagg, a propósito das práticas de poder que constituem regimes de significação visual, vê a cidade planejada que emerge no século XIX como espetáculo, na qual as funções comerciais, residenciais e de lazer encontram-se demarcadas por uma circulação controlada, cujos signos articulam-se também visualmente. Retomando as asserções de Griselda Pollock a respeito da necessidade de ver a cidade não só como resultado da reprodução de classes e eixo do consumo, mas também organizada sob as marcas das diferenciações de gênero, Tagg (1994: 83-86) chama a atenção para a maneira como a presença fe- 
minina é cerceada pelo olhar masculino - “... the eroticized, mobile, free and avaricious gaze of the middle-class, male flâneur, dandy or blood". A mulher é objeto de admiração e curiosidade.

\section{Figura 4}

Homem ao lado de coluna, 1879-1885. Carte de visite em albumina sem título, fotografia de Militão Augusto de Azevedo, álbum v. 6.

Estúdio Photographia Americana. Acervo do Museu Paulista da Universidade de São Paulo.

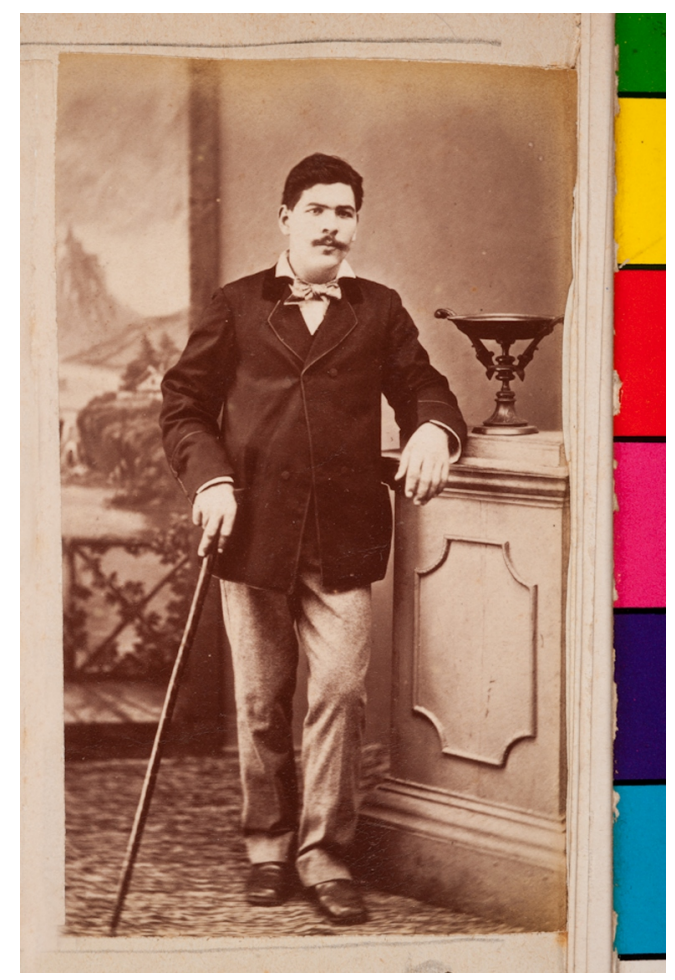

Em São Paulo, o processo de exposição da mulher branca e abastada, de "família", ocorreu de modo gradual, resultado de negociações e adaptações que tiveram suportes na etiqueta, ${ }^{7}$ no vestuário, no ornamento do mobiliário urbano, na decoração arquitetônica e na cenografia do estúdio fotográfico. Wanderley Pinho (1939: 64-97) transcreve inúmeras impressões de viajantes sobre a sociedade paulistana no século XIX. Mesmo após 1870, quando a cidade passa a con- 
tar com uma vida mais movimentada pelo comércio e pela presença dos estudantes, a presença de "senhoras" e "senhoritas" nas ruas era rara e em geral acompanhada de familiares ou marido. ${ }^{8}$ Ernani da Silva Bruno (1984:1161) afirma, com base no relato de um observador anônimo da cidade, que, em 1882, já era possível ver senhoras desacompanhadas olhando as vitrinas na rua 15 de Novembro e adjacências. Mas essa ainda era uma exceção, e não a regra.

\section{Figura 5}

Mulher apoiada em pedra cenográfica, 1879-1885. Carte de visite em albumina sem título, fotografia de Militão Augusto de Azevedo, álbum v.

6. Estúdio Photographia Americana. Acervo do Museu Paulista da Universidade de São Paulo.

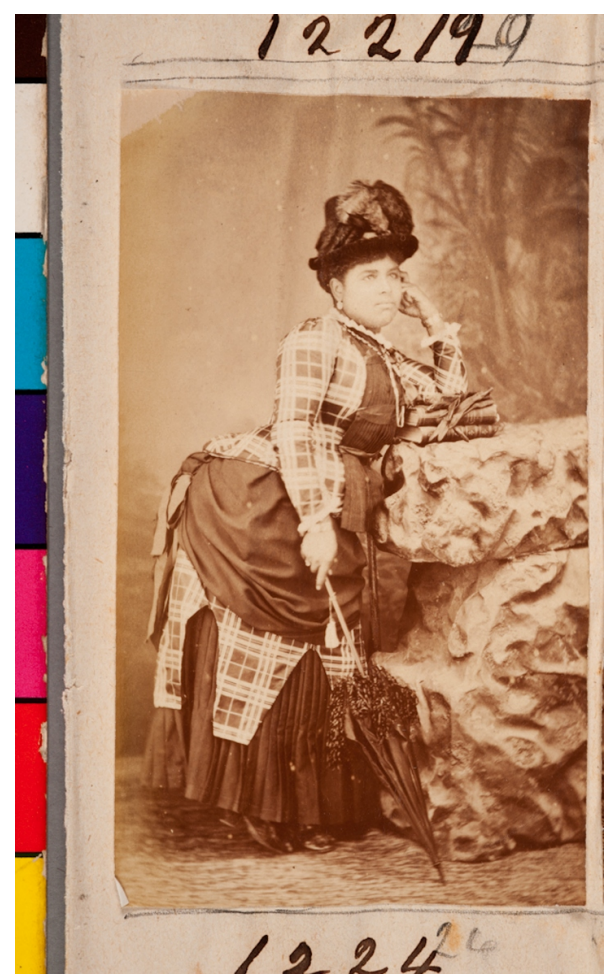

Uma análise quantitativa de retratos produzidos na cidade de São Pau$10^{9}$ aponta diferenças de gênero presentes tanto na simples demanda por um retrato, quanto na forma de homens e mulheres se apresentarem aos olhos de ami- 
gos, pretendentes e familiares. Nessa dinâmica de exposição do corpo no retrato muitas são as aproximações com a situação de exposição do citadino na paisagem urbana. A valorização do meio-corpo e do busto nos retratos é notória. Diferentemente da sociedade aristocrática que valorizava o corpo inteiro, já que havia uma equivalência entre o grau de ostentação de riquezas e o valor social ou moral da figura humana representada, para o homem burguês não é tão direta a associação, obliterada ainda pelas fortes distinções masculinas e femininas que interditou ao homem o acesso explícito à exibição ornamental. Relacionado ao trabalho, especialmente o intelectual, o busto acaba sendo uma forma mais apropriada de visualização da dignidade (Essus, 1995: 99-138). A sobriedade masculina e o destaque do rosto passam a contrastar com a manutenção das formas de exibição aristocráticas para a mulher.

Com a aplicação de descritores que distinguem sexo e faixa etária para o conjunto de 12.178 retratos do arquivo fotográfico de Militão Augusto de Azevedo, verificou-se a predominância da presença masculina adulta (60\%). Metade dos retratados são homens que figuram em imagens individuais. As mulheres retratadas individualmente são apenas $20 \%$. A representação masculina na infância é também mais numerosa. Como nas imagens dos citadinos, os homens se apresentam com roupas urbanas. As funções militares e religiosas, de grande prestígio, estão presentes e as atividades intelectuais e artísticas estão representadas com o porte de livros e palhetas. Em milhares de retratados apenas três apresentam-se com instrumentos de trabalho - serrote, pá e panela. Em uma cidade onde a grande massa da população masculina era pobre, flutuante e ligada aos trabalhos manuais (comércio ambulante, artesanato e serviços urbanos e domésticos em geral) (cf. Pinto, 1994), produzir um retrato usando terno, colete e calça como partes de um mesmo conjunto, além de complementos como cartola, guarda-chuva, bengala e óculos significava distanciar-se dos segmentos sociais desprestigiados e construir uma imagem (real ou ficcional) de respeito e dignidade, que era sinônimo de homens cuja profissão e situação financeira permitiam a adoção da indumentária urbana europeia.

No caso dos retratos de corpo inteiro, os homens apresentam-se em posição ereta, de frente, com leve rotação do corpo ou do rosto para a esquerda ou direita. Do universo de 12.178 retratos do arquivo de Militão, pouco mais de mil unidades não foram recortadas pelo fotógrafo. ${ }^{10}$ Os retratos que restaram íntegros permitem uma análise das posturas dos retratados, enquanto o universo maior permite apenas a identificação do número e do gênero dos retratados. Entre os retratos integrais, 1.150 são individuais de corpo inteiro (759 masculinos e 391 femininos). Para ambos os sexos predomina a pose em pé (86\% do universo de retratos masculinos e $85 \%$ do universo de retratos femininos). 
Para o homem, a exibição do rosto era essencial, não havendo disputas, como no caso feminino, com outras partes do corpo. A equivalência entre ver, fruir, conhecer e controlar encontra na fotografia um campo inesgotável de possibilidades. Assim, a identificação do retratado pelo rosto atende não somente à afirmação de status social. O retrato de estúdio absorve os efeitos da introdução da fotografia em outros circuitos, como o das instituições disciplinares, corregedoras e científicas, que começam a estudar o corpo humano a partir da fotografia (cf. Tagg, 1988).

\section{Figura 6}

Largo S. Francisco. c. 1892. Kowalsky \& Hensler. Reprodução extraída de KOSSOY, Boris. Álbum de Photographias do Estado de São Paulo, 1892.

São Paulo: CBPO/Kosmos, 1984, p. 55.

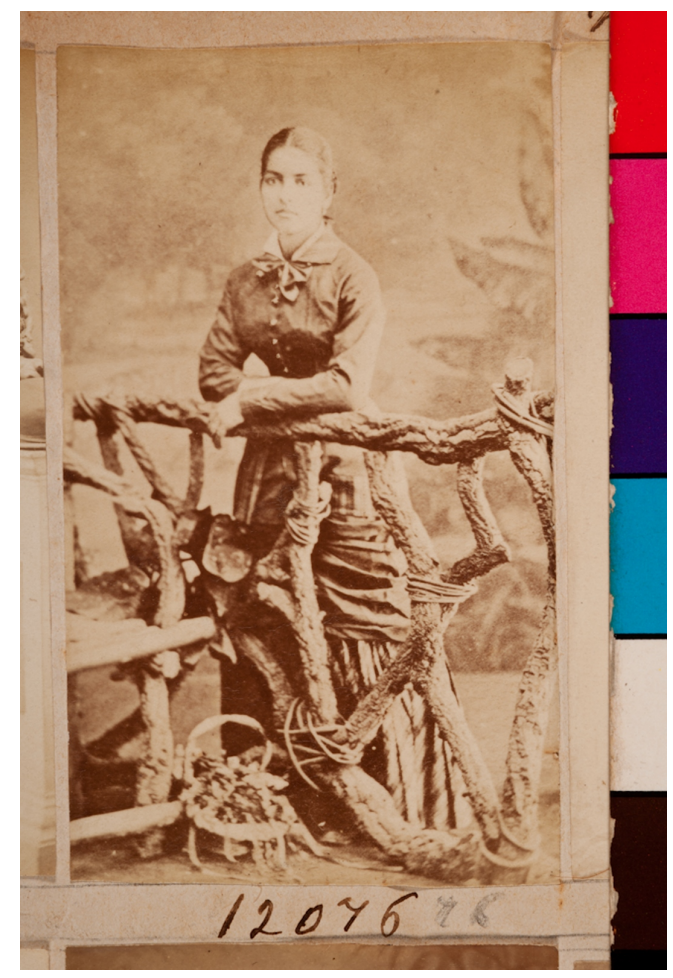

A representação da mulher nas imagens de corpo inteiro tem diferenças significativas. Mais de $40 \%$ das imagens femininas têm a presença da cadeira, cujo espaldar serve de apoio para as mãos na posição ereta. Além disso, a cadeira 
coloca a figura feminina simbolicamente no espaço interno da casa e não na paisagem urbana. A importância do rosto, que nos retratos masculinos é indiscutível, no caso feminino divide seu lugar com o corpo, exacerbado pelo volume e pela ornamentação dos vestidos. As poses laterais, interditadas aos homens, ressaltam as curvas da base da nuca, pescoço e lombar. Interessante observar que a exposição do corpo feminino como ornamento vê-se suavizada quando se trata do espaço público e aberto da cidade. $\mathrm{O}$ anteparo do guarda-corpo parece querer compensar uma superexposição, aceita e incentivada no território privado das residências ou mesmo nos eventos sociais.

Ao isolarmos determinadas posturas e enquadramentos e associá-las ao gênero masculino e feminino cercamos os elementos de uma sintaxe cujo sentido se completa no âmbito de uma cultura visual, que envolve não só a circulação própria do retrato, mas de um modelo masculino de fruição da cidade. Nesse sentido, o retrato é o resultado e, ao mesmo tempo, o gerador de uma linguagem corporal que dá materialidade a práticas sociais específicas.

\section{Figura 7}

Jardim da Luz. c. 1892, Kowalsky \& Hensler. Reprodução extraída de KOSSOY, Boris. Álbum de Photographias do Estado de São Paulo, 1892.

São Paulo:CBPO/Kosmos, 1984, p. 101.

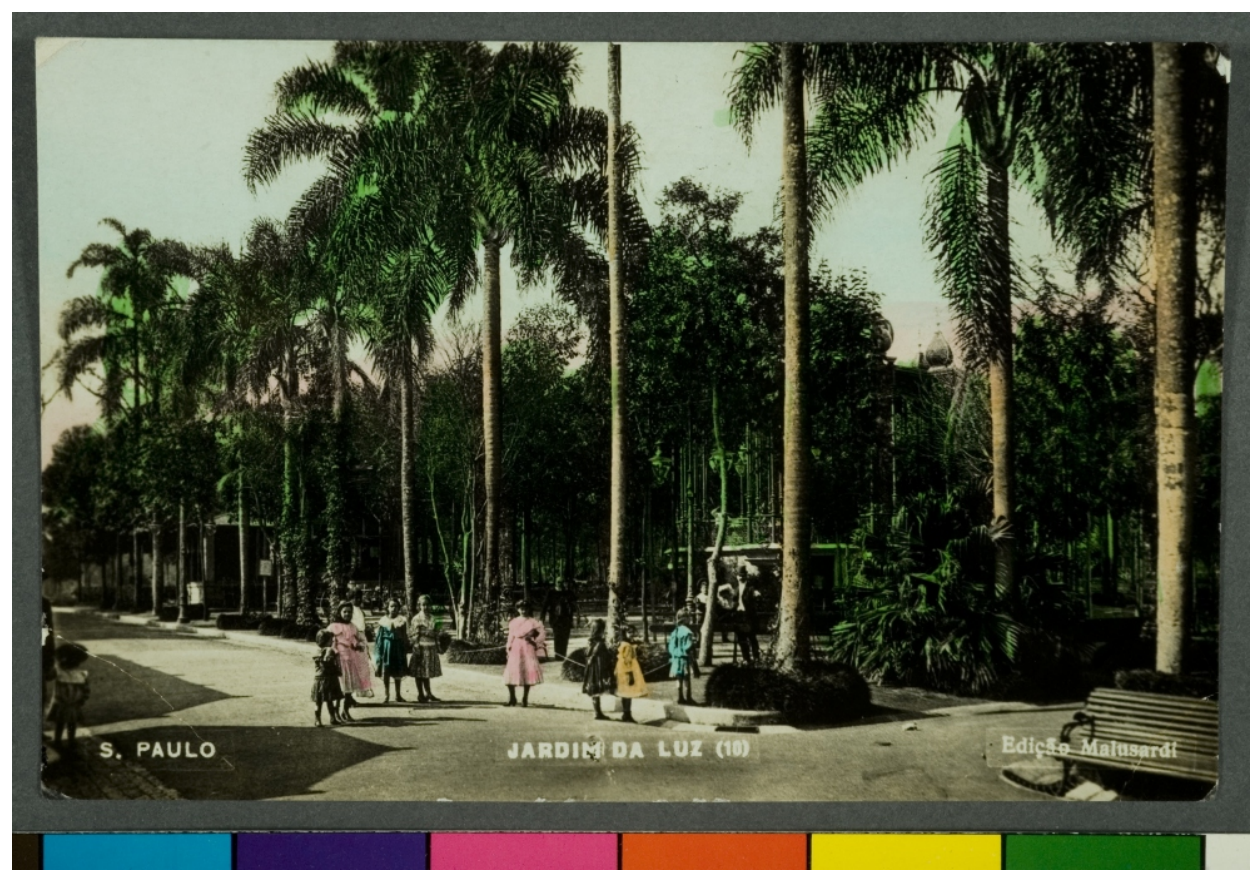




\section{Figura 8}

Avenida Tiradentes e Palácio Episcopal. c. 1892, Kowalsky \& Hensler. Reprodução extraída de KOSSOY, Boris. Álbum de Photographias do Estado de São Paulo, 1892. São Paulo: CBPO/Kosmos, 1984, p. 101.

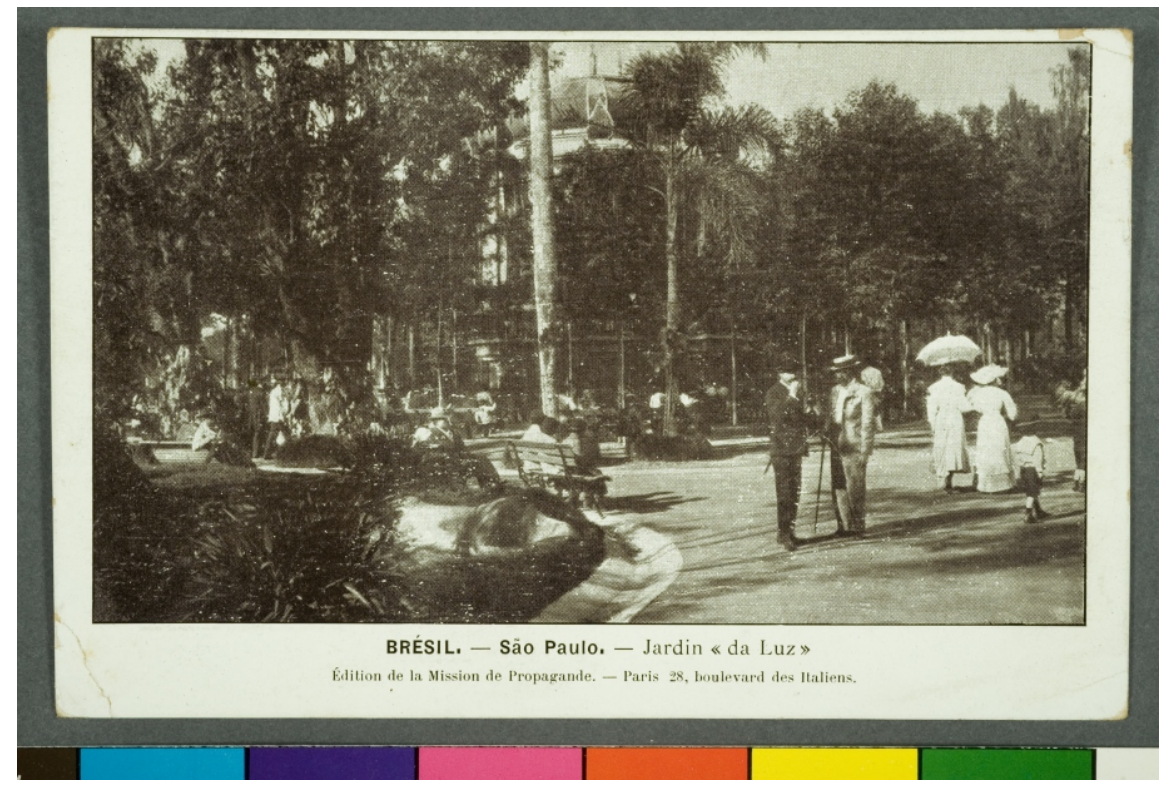

Dada a supremacia do gênero masculino nos espaços públicos da cidade, nas fotografias oitocentistas ${ }^{11}$ que registram a vida paulistana é a figura do homem que aparece como modelo corporal de comportamento em locais públicos. As figuras 6, 7, 8 e 9 fornecem as recorrências desse modelo e seus imprescindíveis aparatos materiais, dignos de pessoas de "fino trato", criadas nos "preceitos da civilidade": o corpo ereto, a cartola, o terno estruturador e suprimido de qualquer sinuose, ${ }^{12}$ a bengala ou o guarda-chuva - acessórios do traje masculino carregados de significados de poder social - e os elemento contra-atuantes, que "compõem" o retratado na paisagem - árvores, postes de iluminação e o gradil, que agora cumpre papel de fundo. Nas fotografias do Jardim da Luz, é recorrente o enquadramento de pessoas nas alamedas junto às árvores. enfatizando-se a verticalidade. A justaposição de árvores e transeuntes na alameda principal consagra um equilíbrio dinâmico, que indica o movimento como modo de fruição do jardim (Figura 7). Homens e mulheres têm o mobiliário urbano ou paisagístico (jardim ou praça) como coadjuvante na construção da cena: ora a luminária esguia e com terminações em volutas de ferro forjado e pedestais esculpidos de ferro fundido, ora o gradil do jardim ou do viaduto. 


\section{Figura 9}

Museu Paulista e Jardim do Ipiranga. Início do século XX.

Desenho de Archibald Forrest em FORREST, Archibald.

A Tour Through South America. London: Stanley Paul \& Co, 1913, p. 307.

http://ia700309.us.archive.org/33/items/tourthroughsouth00forrrich/ tourthroughsouth00forrrich.pdf

Acessado em 22/08/2011.

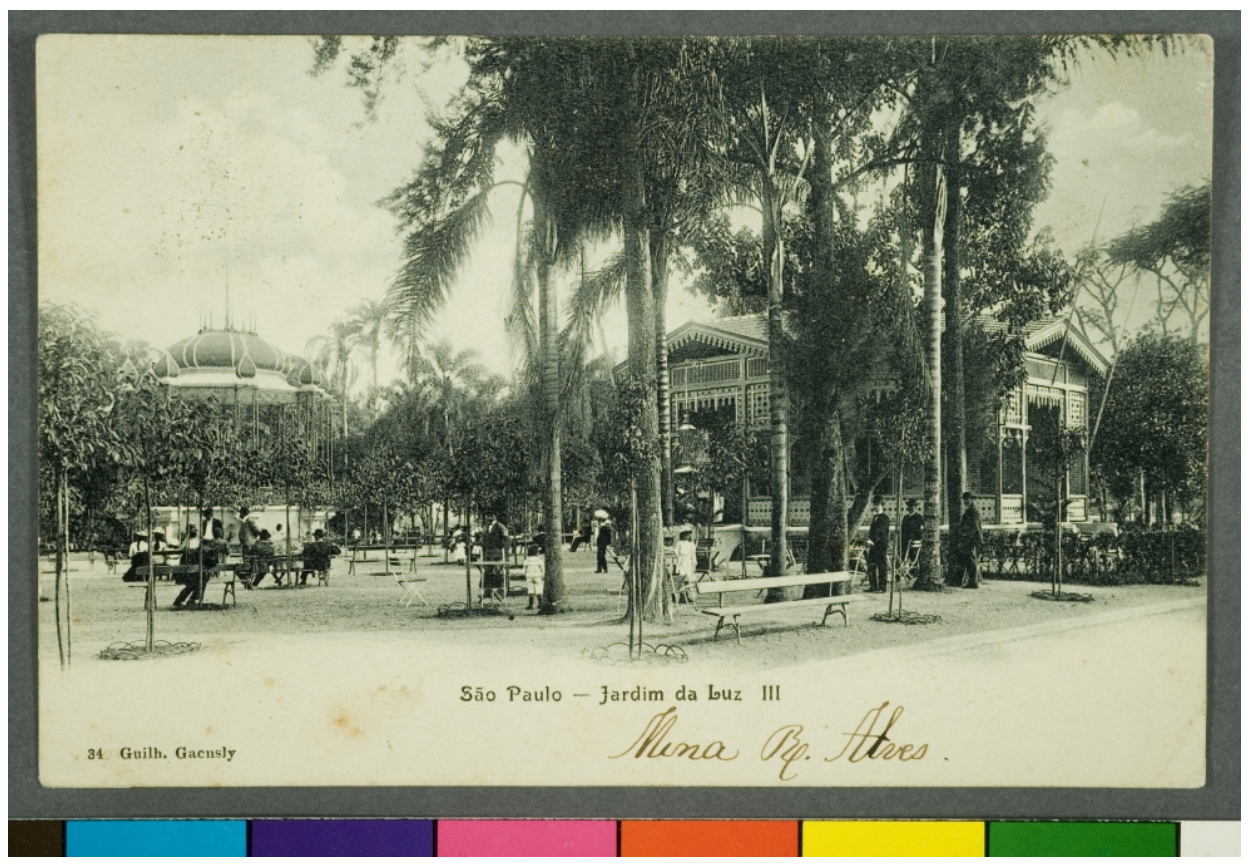

As formas dos mictórios, quiosques e guaritas, não sendo propriamente uma construção, inspiravam-se fortemente no corpo masculino vestido. Não é difícil encontrar ressonâncias formais entre o modelo mais popular de mictório (Figura 10), ${ }^{13}$ de quiosque (Figura 11) e da guarita (Figura 12) e os elementos indispensáveis da moda masculina predominante nos centros urbanos: o paletó ou casaco de corte reto compondo com a cartola tubular ou chapéu. Todos guardam semelhança quanto à estrutura cônica. $\mathrm{O}$ rendilhado nas extremidades funciona não como referência ao vestuário masculino, mas como arremate do objeto, aquilo que se quer pôr em destaque na paisagem.

No mictório, o corpo é oculto por chapa em forma espiral sobre eixo sustentada por varões ornamentados nas pontas com cobertura não contígua. Ao expor pés e cabeça, cria-se a barreira visual para as funções de dejeto, ao mesmo 
tempo em que o controle visual (por quanto tempo e em que postura) é facilitado. Este tipo de controle integraria o que Alain Corbin (1991:454) ao analisar a moral pública e privada chamou de "o cerco à masturbação no séc. XIX". A cobertura contava com vidro e luminária a gás no topo (figura 13).

\section{Figura 10}

Projecto de um Mictório para a Estação de S. Joaquim.

São Paulo, 28 de fevereiro de 1894. Eng. J. O. Nébias. Eng. da Câmara. Documento original. Acervo do Arquivo Washington Luiz. Prefeitura Municipal de São Paulo.

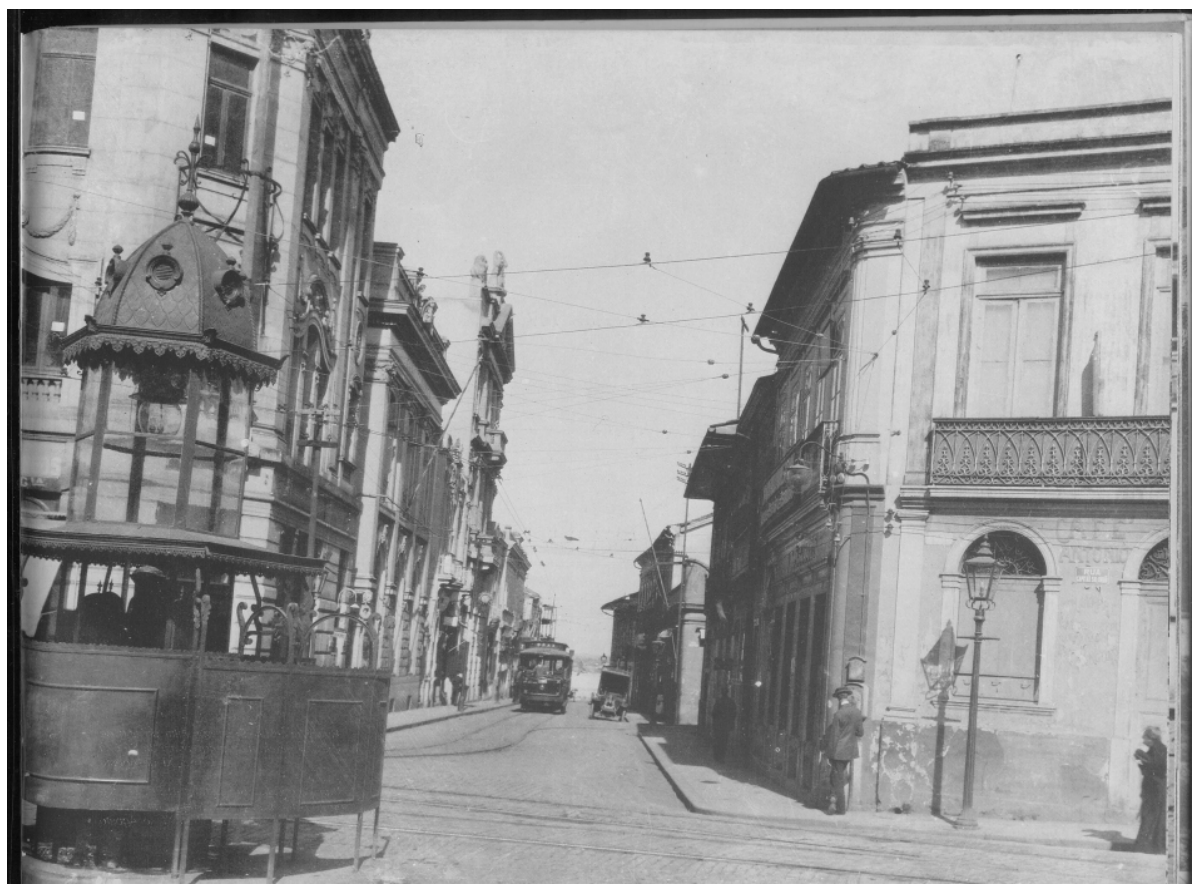

No caso dos quiosques, ${ }^{14}$ a relação com as partes expostas do corpo é outra: a estrutura é circular com aberturas basculantes na metade superior, expondo apenas meio corpo. O meio corpo exposto no quiosque define a postura que privilegia mãos e expressões faciais, mobilizadas na venda de produtos.

Nas guaritas o corpo ganha visibilidade frontal total (figura 12). O corpo inteiro só é mobilizado na atividade de controle e vigilância, no caso das guaritas, pois permite o deslocamento rápido além de garantir a visualização dos aparatos do traje oficial (do exército, guardas etc.). 


\section{Figura 11}

Assentamento de trilhos de bonde na rua do Seminário, 1900.

Reprodução. Acervo da Fundação Patrimônio e Energia de São Paulo.

Reprodução extraída de $A$ Cidade da Light. São Paulo:

Departamento de Patrimônio Histórico/Eletropaulo, 1990, p. 63.

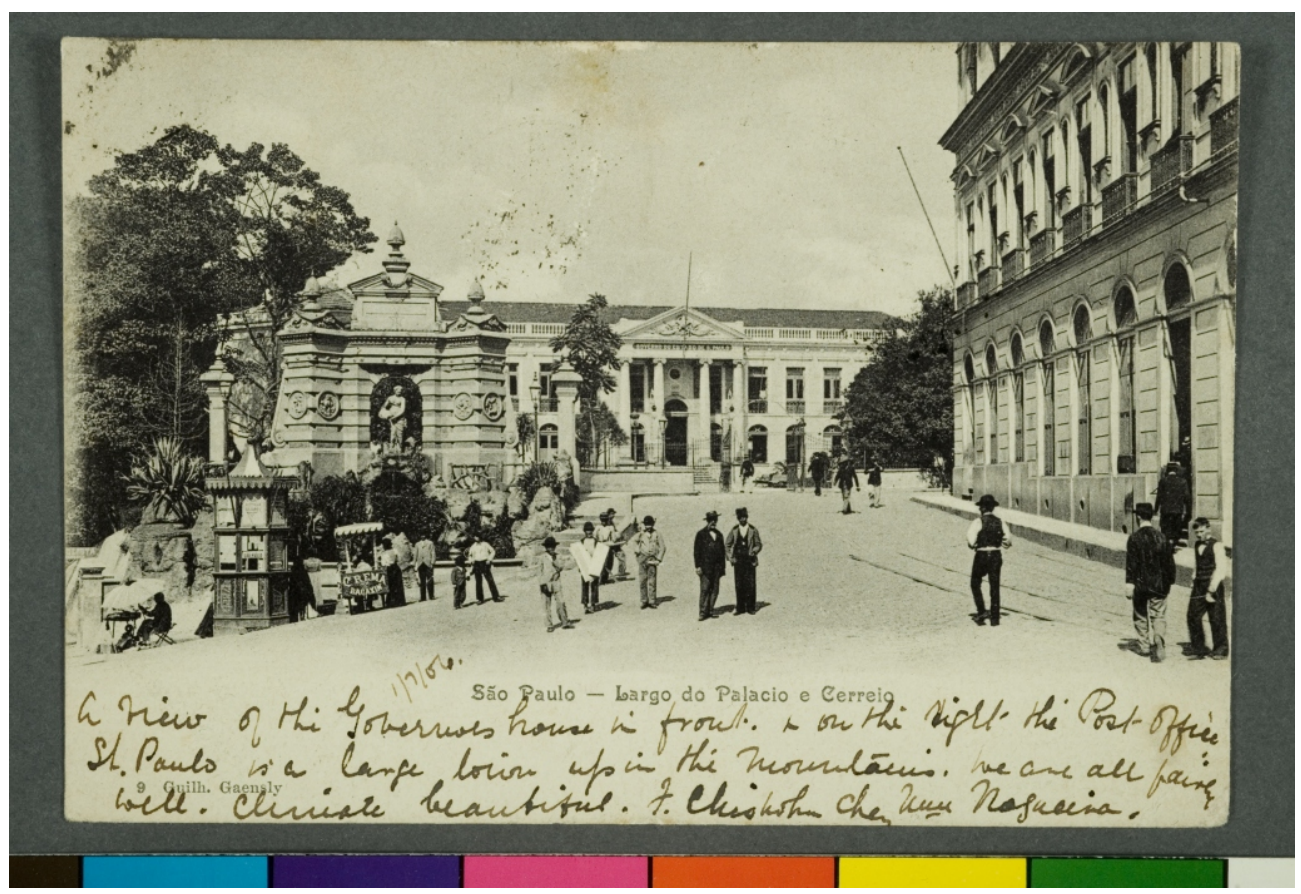

O coreto - projetado para abrigar grupos em atividades voltadas para a exposição pública, além da mesma estrutura e cobertura rendilhada - era dotado de elementos próprios da exposição na residência, os gradis. Diferentemente das demais estruturas acima analisadas, nesse caso a visibilidade é total, graças à elevação e ao cercamento circular vazado. Porém, mantém-se a secção formal do meio do corpo, em virtude do gradil, cuja ornamentação se assemelha àquelas de sacadas, balcões e guarda-corpos.

Assim, para as novas ações aceitas como passíveis de serem desempenhadas publicamente, o mobiliário de ferro desenha um tipo de exposição corporal. Para o consumo, o meio corpo; para a vigilância, o corpo inteiro. Para a emissão de dejetos, cabeça e pés aparecem. Mas, em todos eles, o lambrequim comparece como ornamento aplicado como "arremate" do enquadramento. 


\section{Figura 12}

Palácio Campos Elíseos, residência presidencial. Cartão postal, década de 1900. Acervo particular.

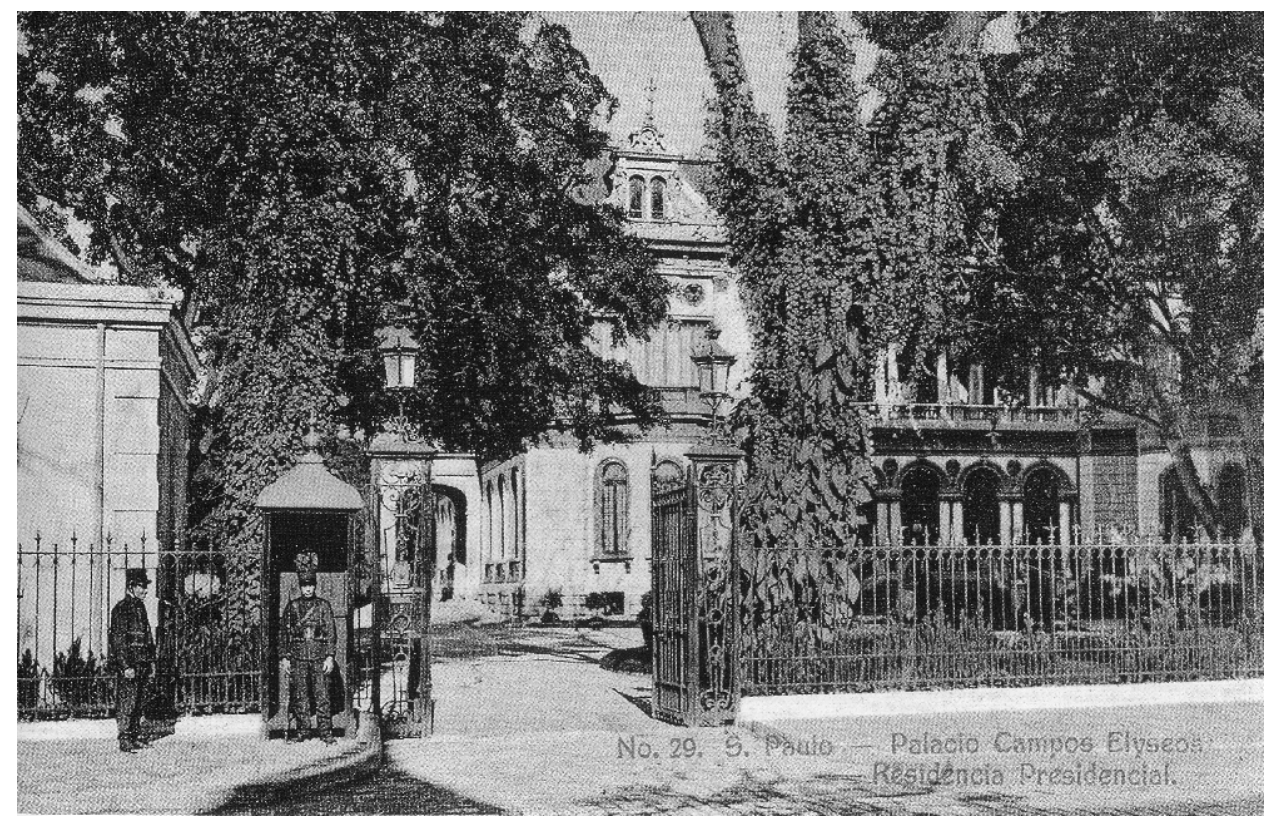

Se a estrutura do mobiliário aqui analisado define diferentes abordagens visuais do corpo, a ornamentação concentrada nas extremidades cria igualdades formais. A referência básica comum a todos, o telhado cônico e rendilhado, remete imediatamente para o traço característico do chalé. Um dos projetos apresentados à Câmara Municipal (1895) para sanitários coletivos chega a denominá-los chalets sanitários. ${ }^{15}$

No vestuário, o ornamento sempre cumpriu funções sinalizadoras e simbólicas de demarcar classes, explicitar categorias profissionais e seus graus (no caso de uniformes e trajes religiosos, por exemplo) e, em relação ao corpo, os elementos ornamentais predominam demarcando os limites entre traje e pele (Snodin \& Howard, 1996:89). As funções de decoro que voluntária ou involuntariamente sacadas e balcões acabam por cumprir ao "filtrar" a exposição do corpo inteiro teriam paralelo com movimento semelhante apontado por Gilda de Melo e Souza (1984: 93) na trajetória da moda e vestuário do século XIX. ${ }^{16}$ O ritmo da moda integra-se a um movimento maior, que coloca em foco a exposição e a circulação dos corpos na cidade e a própria ideia de consumo visual. 


\section{Figura 13}

Largo da Misericórdia, c. 1910.

Reprodução extraída de $A$ Cidade da Light. São Paulo:

Departamento de Patrimônio Histórico/Eletropaulo, 1990, p. 183.

Acervo da Fundação Patrimônio Histórico da Energia de São Paulo.

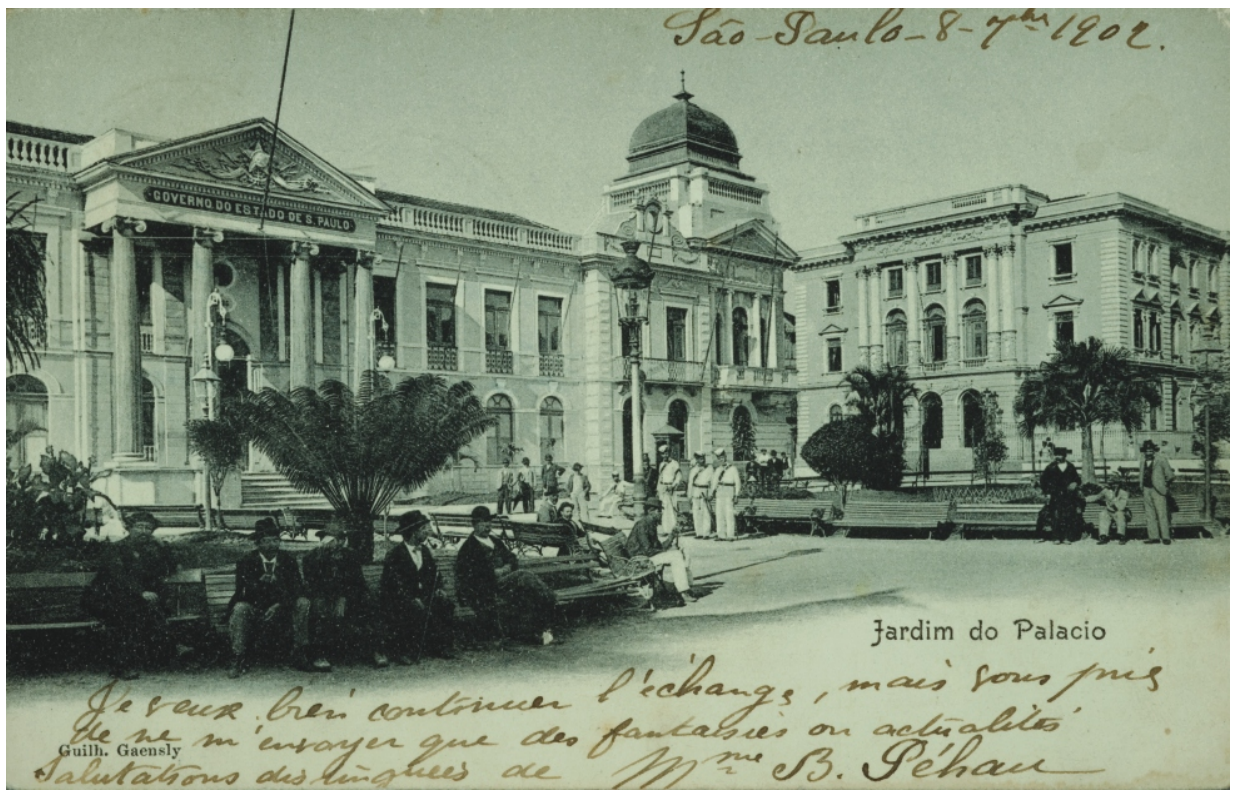

Em dupla mão, as molduras visuais e a interação corpo e mobiliário urbano fornecem o substrato para mapear os primeiros efeitos de uma abordagem que valoriza a aparência visual da cidade. Mictórios e quiosques no espaço público aberto sugerem um prolongamento de funções exercidas no espaço privado, ou da privacidade para o controle citadino. As aproximações formais entre as coberturas dos chalés e das estruturas móveis na cidade, além de ancorarem-se na familiaridade, ajudam a estabelecer um conteúdo material específico para o que vem a ser "moderno", "belo" ou "artístico".

A especificidade deste conteúdo é fundamental, pois implica aceitar que ele é mutável, sobretudo na virada do século XIX para o XX, momento em que a cidade se constituía simultaneamente como espetáculo e objeto do pensamento urbanístico e artístico (Tagg, 1994: 84-85). As representações urbanas estão em processo de gestação, ao mesmo tempo em que a cidade física e seus problemas concretos de infraestrutura e circulação se delineiam. A presença de uma tipologia de mobiliário urbano representa uma primeira tentativa de inserir e contro- 
lar as ações individuais no espaço público. Coubera ao desenho da forma e à ornamentação destes móveis para espaços abertos criar a familiaridade necessária que induzisse a sua aceitação e uso.

\section{Sentar-se: ócio e conforto}

Se a pose ereta é a marca do homem público, a pose sentada é associada ao interior residencial, dada a presença de mobiliário próprio da sala de visitas. ${ }^{17}$ O interior burguês transforma-se em uma experiência possível a partir do estúdio fotográfico, numa época em que quase nenhuma casa assimilara a ideia de sala de visitas como espaço de representação de status, ostentação e negociação social (Lemos, 1983: 57,58). Percebe-se, portanto, nos retratos, como as demarcações entre público e privado mudam, o primeiro adentrando o interior das residências para formar aquilo que identificamos como as áreas sociais da casa sala de visitas e sala de jantar, especialmente.

\section{Figura 14}

Grupo de homens e menino em diferentes poses apoiados em pedra cenográfica, 1879-1885. Carte de visite em albumina sem título, fotografia de Militão Augusto de Azevedo, álbum v. 6. Estúdio Photographia Americana. Acervo do Museu Paulista da Universidade de São Paulo.

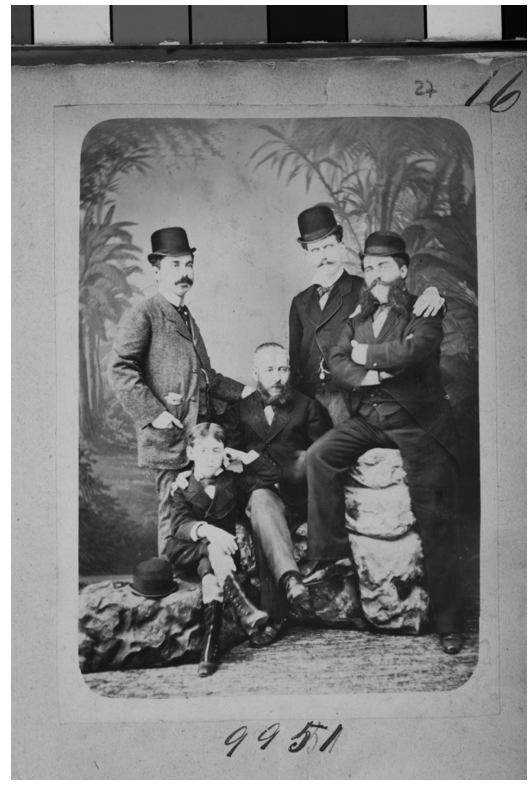


Os retratos de casais articulam-se a essa nova modalidade pública na casa, mas nos mostram como homens e mulheres a vivenciaram de modo diferente. No caso dos retratos de casal (634 ao todo), quase metade (48\%) são de homens e mulheres em pé. No entanto, o segundo padrão mais recorrente é aquele em que a mulher aparece em pé e o homem sentado. Além do acesso masculino privilegiado à cadeira, as imagens de grupos masculinos nos indicam uma maior riqueza de posturas corporais que variam entre a extremamente rígida até aquela completamente informal - pernas relaxadamente abertas, uso da mesa como assento ou encosto, corpo recostado etc. Tais retratos nos dão os primeiros indícios da importância do sentar-se na constituição da identidade masculina, a qual cria ligações explícitas com as noções de conforto corporal e poder (figura14).

Fotografias da paisagem urbana que privilegiam pessoas sentadas nos bancos de praças e jardins são mais escassas e estão longe de possuir a variedade do sentar-se observada nas figuras masculinas presentes nos ateliês fotográficos. A etiqueta do sentar-se publicamente, em espaços abertos da cidade, é mais rígida, já que se faz necessário distinguir o cidadão que frui a cidade daquele que se deixa simplesmente estar. No comentário do livro Il Brasile e gli italiani, publicação de 1906 (apud Kossoy, 1988: 22), a associação entre sentar e estar desocupado é indicativa de certas diferenças entre aqueles que passeiam pelos jardins, praças e parques, atividade disciplinada por horário e, portanto, dentro de um quadro social regulado, e a vadiagem:

O Largo do Palácio, habitualmente quieto e frequentado apenas pelo mundo oficial e pelos desocupados que passam longas horas nos bancos de jardim, assume um aspecto alegre e animadíssimo quando ali se faz ouvir a ótima banda musical da polícia e, naqueles dias de festa nacional, quando então a tropa sai nos seus vistosos uniformes para a revista.

\section{De homem público a transeunte}

Durante a primeira década do século XX, apesar das regras de decoro público aplicadas à exposição do corpo na paisagem urbana e de sua natureza disciplinadora, mictórios e quiosques possibilitaram o uso não discriminado de equipamentos antes disponíveis somente em ambientes fechados e privados (banheiros residenciais, cozinhas, restaurantes). Não tardou para que tais equipamentos fossem considerados símbolos de insalubridade e obstáculos 


\section{Solange Ferraz de Lima e Vânia Carneiro de Carvalho}

para as necessidades cada vez mais fortes de equacionamento de problemas de fluxos de veículos.

Sem abandonar as associações entre embelezamento, civilidade e higiene, as ações do poder público, fartamente documentadas, passam a priorizar cada vez mais a circulação, transformando, por exemplo, largos cercados, como o jardim do largo de São Bento, em rotatórias (Carvalho \& Lima, 1997: 131).

Nessa nova equação de cidade, mictórios e quiosques, ao apresentarem uma solução individual para as relações e ações dos corpos no espaço público, destoam da vocação de circulação pretendida, sobretudo para a área central da cidade. Se em um primeiro momento sua presença material validou e facilitou o reconhecimento de uma vida moderna - por trazer, para o espaço da rua, comodidades do espaço fechado privado (o banheiro), ou do abastecimento rápido e em trânsito de alimentos ou bebidas (quiosques) -, eles não têm mais lugar na cidade do século XX. O banimento dos quiosques e mictórios ocorre sob a pressão de imagens que os associam à sujeira e à desordem. Os mictórios, apesar de sobreviverem até a segunda década do século XX, em São Paulo, eram o alvo predileto das críticas feitas nos jornais à falta de limpeza pública, razão pela qual foram deslocados para pontos de pouca circulação. No caso dos quiosques, a ação foi radical e eles desaparecem já no início da década de $1900 .{ }^{18}$

No caso dos jardins públicos, assiste-se igualmente a um redirecionamento no que se refere ao seu conceito e estética. Se os portões de ferro marcaram as feições materiais da disciplina que garantia a fruição nos espaços públicos no século XIX, já no século XX eles começam a desaparecer, sob a influência de um novo tipo de paisagismo urbano. Os jardins e as praças sem portões são fruto de uma visão urbanística preocupada em integrar a natureza à totalidade da cidade (Le Dantec, 1996: 292). Os projetos de parques públicos para cidades americanas de Frederik Law Olmsted (1822-1903) revolucionaram a relação entre parque e sistema de ruas. São de sua autoria o sistema de parques de Boston, o entorno do Capitólio, em Washington, o Central Park e o Prospect Park, em Nova York (Le Dantec, 1996: 292). O Central Park, seu projeto mais conhecido, promove uma interação não mediada por portões ou grades entre a cidade e o parque. Implantado no coração da ilha de Manhattan, o projeto prevê alamedas que garantem a circulação entre ambos os lados do parque, integrando-o à circulação urbana. Outra imagem de cidade moderna se impõe. Não há mais lugar para o jardim ou parque como um "refúgio" cercado da agitação da cidade. A presença da natureza transformada em paisagem se oferece agora para a fruição em trânsito.

Acompanhar a trajetória de inserção do ferro ornamental no mobiliário urbano e do cercamento de espaços públicos abertos evidenciou um conteúdo específico das relações sociais que se instauraram no bojo da primeira modernização 
da estrutura e da aparência de São Paulo. Igualmente, flagrar seu desaparecimento é revelador de outro momento de inflexão na evolução urbana. As mudanças na conceituação de jardins públicos, que culminam com o desaparecimento de seus gradis e portões, não atingem os jardins privados. $\mathrm{O}$ ferro ornamental do cercamento das propriedades privadas não desaparece nesse período. Os exemplos presentes nas matérias publicadas nas revistas de variedades são inúmeros.

Em uma das crônicas da revista $A$ Cigarra de dezembro de 1915, comenta-se que os jardins da cidade ainda se encontravam aquém do que deveriam ser: "Por enquanto o jardim, para umas tantas pessoas ainda é um problema insolúvel. A evolução esthetica está muitíssimo distanciada da evolução moral...". ${ }^{19} \mathrm{Se}$ durante o século XVIII as criações e inovações para jardins restringiram-se aos espaços privados aristocráticos, a tônica no século XIX desloca o interesse para os espaços públicos. No início do século XX, os jardins privados mantêm sua importância, em meio a uma crise de incompatibilidade entre jardins em espaços públicos e as novas exigências da cidade industrial (Le Dantec, 1996: 319). Esse movimento não se expressou nas cidades brasileiras ao mesmo tempo, mas certamente influenciou a valorização dos jardins privados, que contavam com revistas especializadas, tratados e manuais estrangeiros para sua criação. Mas em que medida jardins, estética e moral se imbricavam a ponto de merecerem ser tratados de maneira tão banal por uma revista de variedades?

A resposta mais imediata diz respeito à associação entre aparência e cidadania. Cidadãos evoluídos e civilizados cuidam de sua aparência e da aparência de suas residências. $\mathrm{O}$ jardim bem cuidado revela o tipo de cidadão morador. Em outras palavras, a evolução moral necessita de uma exteriorização concreta, material, e o tratamento estético dos jardins seria uma das formas desta exteriorização.

É justamente para o "embelezamento" da cidade ${ }^{20}$ que a municipalidade concentra as intervenções urbanísticas levadas a cabo nas duas primeiras décadas do século XX. Estas podiam ser plenamente justificadas se o argumento remetesse a uma imagem moderna, possível de ser alcançada pela abordagem tecnicista do espaço e tendo como horizonte sua apropriação estética. A concretização da ideia de cidade embelezada e moderna, no entanto, dependeu do compartilhamento de imagens - visuais e literárias -. capazes de proporcionar a familiaridade com o comportamento adequado a essa nova paisagem urbana, por meio de suportes como as revistas, jornais, poemas e a fotografia, difundidos na sociedade paulistana. 
Notas

1. Parte-se do sentido mais restrito de paisagem como "objeto espacial de apropriação estética" para chegar-se aos sentidos e aos usos sociais, ou seja, à noção de paisagem como prática social (cf. Meneses, 2002, 2001).

2. Engenheiro-arquiteto alemão (18611916) e professor da Escola Politécnica, Hehl foi um dos mais conhecidos e atuantes arquitetos da cidade, tendo trabalhado no escritório de Ramos de Azevedo. É o autor do projeto da catedral de São Paulo, em estilo gótico.

3. Periódico dedicado a variedades e noticioso da vida social das classes mais abastadas da cidade.

4. Para exemplos de molduras fotográficas em álbuns, ver Carvalho \& Lima, 2009: 412, 413.

5. Fotógrafo suíço (1843-1928) radicado no Brasil, Gaensly é responsável pelo maior número de fotografias que caracterizam as feições "modernas" ou a "cidade eclética" de São Paulo, no início do século XX. Contratado pela Light para documentar suas obras e intervenções na cidade (1900), e também pelo governo estadual e pela Prefeitura (1901-1902), ele veiculou imagens sob a forma de cartões postais e as comercializou para a produção de álbuns fotográficos (cf. Kossoy, 1988; Carvalho \& Lima, 1997; Mendes, 2001).

6. Para a noção de retratística como prática social integrante, inclusive, dos processos orais de comunicação ver o estudo dos retratos setecentistas ingleses realizados por Marcia Pointon (1993:5).

7. Entendida como conjunto de regras que regulam as posturas, gestualidade e linguagem em público.
8. Não é ocioso lembrar que Maria Odila L. Silva Dias e Paulo César Garcez Marins já demonstraram que as ruas, sim, eram frequentadas por mulheres. Além de negras escravas, transitavam pela cidade mulheres brancas pobres, cabeças de família que traziam alimentos cultivados das roças dos arrabaldes, faziam comércio, e as mulheres de famílias decadentes, que empobrecidas, esgueiravam-se pelas ruas para tratar, da mesma forma que as demais, de sua sobrevivência. Assim, quando se afirma que a presença feminina era rara, devese ter em mente as prescrições seguidas por mulheres abastadas que, aos poucos, foram ganhando as ruas por conta dos novos hábitos de consumo e de exposição espetaculosa que o passeio na cidade proporcionava (Dias, 1984; Marins, 2001).

9. As considerações que adiante passamos a desenvolver partem da análise morfológica, ainda que parcial, de uma coleção de mais de 12.000 retratos fotográficos produzidos por Militão Augusto de Azevedo, na cidade de São Paulo (Brasil), entre os anos de 1862 e 1885 . A maioria dos retratos foi feita originalmente no formato carte de visite e uma pequena parte no formato cabinet portrait. Todas as unidades encontram-se coladas em seis álbuns, sendo que grande parte dos retratos foi recortada antes de ser fixada e numerada pelo fotógrafo. As páginas dos álbuns nos introduzem em um universo diferente, marcado pela heterogeneidade de milhares de retratos de homens, mulheres e crianças de vários segmentos sociais.

10. Para montar seus álbuns-mostruários e de controle de negativos, Militão recortava as fotografias, retendo apenas o rosto, em forma ovalada, do retrato, que era então colado no álbum e numerado. 
11. As referência iconográficas aqui utilizadas são a Coleção Militão Augusto de Azevedo (fotografias de 1862 e 1887, avulsas e aquelas organizadas no seu Álbum Comparativo da cidade de São Paulo, 18621887. São Paulo: Photographia Americana, 1887), a produção oitocentista de Guilherme Gaensly, Kowalsky e Hensler (Kossoy, 1984) e os cartões postais produzidos entre 1900 e 1920 (Gerodetti \& Cornejo, 1999).

12. O H sugerido por Gilda de Melo e Souza (1987:86) em sua análise formal das diferenças de gênero no vestuário ocidental do século XIX, em oposição à forma do $\mathbf{X}$ do traje feminino.

13. Dos 13 projetos de mictórios localizados no Arquivo Municipal, dois aparecem com certa incidência em diferentes pontos da cidade entre 1890 e 1910 . As discussões sobre a necessidade de mictórios no espaço público tiveram início na Câmara Municipal, muito provavelmente, na década de 1880. No Código de Posturas de 1886, há referências à necessidade de urinadores na cidade, que serão providenciados, mas enquanto isso são estipuladas multas para quem urinar nas vias públicas. Em 1895, a Lei municipal $\mathrm{n}^{\circ} 74$ autorizava a construção de 15 mictórios. Muito provavelmente, os mictórios construídos seguiram o projeto de J. O. Nébias, apresentado à Câmara em 28 de fevereiro de 1894, pois este está presente na grande maioria das fotografias do centro de São Paulo entre 1890 e 1916 . Um ano após a lei de 1895 , uma resolução $\left(\mathrm{n}^{\circ} 72\right.$, de 25 de julho de 1896) proíbe a colocação dos mictórios no centro de largos da cidade, designando "os recantos e logares mais apropriados". A Intendência da Polícia e Higiene fica encarregada de remover os mictórios já instalados para os novos pontos. A motivação da resolução pode ter sido o abaixo-assinado que moradores do largo da Misericórdia enviam, em 21 de janeiro de 1896, à Intendência de Higiene reclamando do mau estado em que se encon- trava o mictório ali instalado (Livro de Protocolo, v. 732).

14. Os quiosques foram uma verdadeira febre na capital paulista no último quartel do século XIX, mas que durou relativamente pouco tempo. Nuto Santana (1939: 37-55) dedica três capítulos a eles. Com base nos projetos e pedidos de autorização para a instalação de quiosques, nos protestos de habitantes e comerciantes contra os mesmos enviados à Câmara Municipal entre 1883 e 1890, Nuto Santana descreve a disseminação e a decadência dos quiosques, referindo-se inclusive à existência da Empresa Industrial de Kiosques (Santana, 1939:55). Embora Ernani da S. Bruno os caracterizasse como sendo integralmente construído de madeira, fotografias permitem identificar coberturas de ferro, com ornamentação nas extremidades, a exemplo dos mictórios e coretos.

15. Projeto de Chiquinho Amaral, apresentado à Câmara em 1895.

16. "É sabido que a vestimenta se origina menos no pudor e na modéstia do que num velho truque de, através do ornamento, chamar a atenção sobre certas partes do corpo. (...) Desde então duas tendências têm-se manifestado nas variações sucessivas da moda: a de devassar o corpo fazendo com que o exibicionismo triunfe sobre o pudor, o instinto sexual expandindo-se em formas mais realísticas de expressão, e a de cobri-lo de disfarces, sob a coação do puritanismo e do decoro. A primeira atitude, bastante rara, acompanha, na maioria das vezes, as grandes crises sociais e o afrouxamento da moral, como nos períodos que sucedem às guerras napoleônicas e ao conflito de 1914. A segunda, mais comum, caracteriza quase todo o século XIX e parte do século XX. Contudo, aqui mais do que lá, é evidente aquele compromisso de que falamos e que conduz a um autêntico recalque, à 


\section{Solange Ferraz de Lima e Vânia Carneiro de Carvalho}

acentuação simbólica das características sexuais" (Souza, 1987: 93).

17. Carlos Lemos em seu artigo Ambientação ilusória (Moura, 1983: 61) chama a atenção para o fato do mobiliário dos estúdios brasileiros ser, na maioria, rebuscado - poltronas de veludo, entalhados ao gosto mais europeu: "O interessante é que esses ambientes, confinados nos ateliês, talvez por terem sido imaginados e trazidos pelos fotógrafos de seus países de origem, nunca reproduzem interiores comuns às casas brasileiras. [...] nunca vemos ali uma simples cadeira Luiz Felipe de palhinha trançada, ou uma prosaica poltrona austríaca, já tão em moda”.

18. Processo semelhante ocorre na cidade do Rio de Janeiro. A crítica que o cronista da época Luiz Edmundo faz aos quiosques do Rio de Janeiro formaliza a tônica da guerra motivada pelo controle social e dos corpos embutido nas preocupações higienistas: "Espelunca fecal, empestando à distância e em cujo bojo vil um homem se

\section{Referências bibliográficas}

\begin{abstract}
AMERICANO, Jorge. São Paulo naquele tempo: 1895-1915. São Paulo: Saraiva, 1957.

BELLUZZO, Ana Maria. Artesanato, arte e indústria. Tese (Doutorado em Arquitetura e Urbanismo), Faculdade de Arquitetura e Urbanismo, São Paulo, Universidade de São Paulo, 1988.
\end{abstract}

BRILLIANT, Richard. Portraiture. Londres: Reaktion Books, 1991.

BRUNO, Ernani da Silva. Memória da cidade de São Paulo: depoimentos de moradorese visitantes, 1553-1958. São Paulo: Prefeitura Municipal de São Paulo/Secretaria Mu- engaiola, vendendo ao pé-rapado vinhos, broas, café, sardinha, côdoas de pão dormido, fumo, lascas de porco, queijo, bacalhau" (Edmundo, 1983:117). Odores na cidade, a lembrança dos dejetos humanos e do corpo aprisionado ("em cujo bojo vil um homem se engaiola") são as impressões negativas que o autor apresenta para atacar aquilo que, de fato, era a razão principal da reação aos quiosques: o comércio ambulante, popular, fora do controle da administração pública e que atraía o "pé-rapado", ou seja, a população pobre.

19. Editorial. A Cigarra, São Paulo, 8 de dezembro de 1915, $\mathrm{n}^{\circ} 32$, p. 5.

20. O termo embelezamento começa a ser usado já na administração de João Theodoro, o primeiro presidente da província de São Paulo (1872-1875) a implementar mudanças no desenho urbano da cidade, como, por exemplo, o alargamento e o alinhamento de ruas, o calçamento e a ampliação do Jardim da Luz. nicipal de Cultura/Departamento do Patrimônio Histórico, 1981.

- História e tradições da cidade de São Paulo. São Paulo: Hucitec, 1984.

BUCK-MORSS, Susan. The Dialects of seeing: Walter Benjamin and the Arcades Project. Cambridge: The MIT Press, 1990.

CARVALHO, Vânia Carneiro de. Gênero e artefato: o sistema doméstico na perspectiva da cultura material. São Paulo, 1870-1920. São Paulo: EDUSP/Fapesp, 2008.

\& LIMA Solange Ferraz de. Vistas urbanas, doces lembranças: o "antigo" e o 
“moderno" nos álbuns fotográficos comparativos. In: An- tigos e modernos, diálogos sobre a (escrita da) história. São Paulo: Alameda Casa Editorial, 2009, p. 397-426.

- \& - Fotografia no Museu: o projeto de curadoria da Coleção Militão Augusto de Azevedo. Anais do Museu Paulista, São Paulo, vol. 5, 1997, p. 205-245.

\& - Individuo, Género y Ornamento en los retratos fotográficos, 1870-1920. In: AGUAYO, Fernando \& ROCA, Lourdes (orgs.). Imágenes y Investigación Social. México: Instituto Mora, 2005, v. 1, p. 271-291.

CORBIN, Alain. Saberes e odores. In: DUBY, Georges (org.). História da vida privada. São Paulo: Companhia das Letras, 1991.

COSTA, Cacilda Teixeira da. $O$ sonho e a técnica. A arquitetura de ferro no Brasil. São Paulo: EDUSP, 1994.

DIAS, Maria Odila L. da Silva. Quotidianoe poder em São Paulo no século XIX. São Paulo: Brasiliense, 1984.

EDMUNDO, Luiz. O Rio de faneiro de meu tempo. Rio de Janeiro: Imprensa Nacional, 1983.

ESSUS, Ana Maria Mauad. Resgate de memórias. In: SCHNOOR, Eduardo \& CASTRO, Hebe Maria Mattos de. Resgate, um janela para o oitocentos. Rio de Janeiro: Topbooks, 1995, p. 99-138.

FREYRE, Gilberto. Sobrados e mucambos. Rio de Janeiro: José Olympio. 1951.

GERODETTI, João Emílio \& CORNEJO, Carlos. Lembrança de São Paulo, a capital paulista nos cartões-postais e álbuns de lembranças. São Paulo: Studio Flash, 1999.

HAMLIN, Alfred Dwight Foster. A History of Ornament. New York, 1916-1925. Nova York: Harper, 1966.
KOSSOY, Boris. Álbum de photografias do Estado de São Paulo. São Paulo: Kosmos, 1984.

São Paulo, 1900. São Paulo: CBPO/ Kosmos, 1988.

LIMA, Solange Ferraz de. Ornamento e cidade - ferro, estuque e pintura mural em São Paulo, 1870-1930. Tese (Doutorado em História Social). São Paulo, Faculdade de Filosofia, Letras e Ciências Humanas, Universidade de São Paulo, 2002.

LE DANTEC, Jean-Pierre. Fardins et Paysages. Paris: Larousse, 1996.

MARINS, Paulo César Garcez. Através da rótula - sociedade e arquitetura no Brasil, séculos XVII a XX. São Paulo: Humanitas / FFLCH / USP, 2001.

MENDES, Ricardo et alii. Imagens de São Paulo: Gaensly no acervo da Light, 18991925. São Paulo: Fundação Patrimônio Histórico da Energia de São Paulo, 2001.

MENESES, Ulpiano T. Bezerra de. A paisagem como fato cultural. In: YÁZIGI, Eduardo (org.). Turismo e paisagem. São Paulo: Contexto, 2002, p. 29-64.

Prefácio. Cidade capital, hoje? In: SALGUEIRO, Heliana Angotti (org.). Cidades capitais do século XIX. Racionalidade, cosmopolitismo e transferência de modelos. São Paulo: EDUSP, 2001, p. 9-17.

MOURA, Carlos Eugênio Marcondes de (org.) Retratos quase inocentes. São Paulo: Nobel, 1983.

MOURA, Paulo Cursino de. São Paulo de outrora. Evocações da metrópole. São Paulo: Livraria Martins, 1943.

NICOLETTI, Roberto. O ferro como ornamento na arquitetura de Bragança Paulista no período de 1890/1930. Dissertação (Mestrado em Arquitetura e Urbanismo), Escola de Comunicação e Artes, São Paulo, Universidade de São Paulo, 1978. 
ORVELL, Miles. Photography and the Artifice of Realism. In: ORVELL, Miles. The Real Thing. Imitation and Authenticity in American Culture. 1880-1940. Chapel Hill e Londres: The University of North Carolina Press, 1989, p.73-102.

PINHO, Wanderley. Salões e damas no Segundo Reinado. São Paulo: Livraria Martins, 1939.

PINTO, Maria Inez Machado Borges. Cotidiano e sobrevivência: a vida do trabalhador pobre na cidade de São Paulo, 1890-1914. São Paulo: Edusp/Fapesp, 1994.

POINTON, Marcia. Hanging the Head. Portraiture and social formation in Eighteenth Century England. Londres/New Haven: Yale University Press, 1993.

RODRIGUES, José Wasth. Documentário arquitetônico. São Paulo: Edusp, 1975.
SANTANA, Nuto. São Paulo histórico. São Paulo: Departamento de Cultura, vol. 3, 1939.

SEGAWA, Hugo M. Ao amor do público: jardins no Brasil. São Paulo: FAPESP/Studio Nobel, 1996.

MELLO E SOUZA, Gilda de. Oespírito das roupas. A moda no século XIX. São Paulo: Companhia das Letras, 1987.

TAGG, John. The Burden of Representation: Essays on Photographies and History. Armherst: University of Massachussetts Press, 1988.

. The Discontinuous City: Picturing and the Discursive Field. In: BRYSON, Norman; HOLLY, Michael Ann \& MOXEY, Keith (eds). Visual Culture. Images and Interpretations. Londres: University Press of New England, 1994.

\section{Resumo}

$\mathrm{O}$ artigo trata da cultura material mobilizada na construção da imagem pública de homens e mulheres a partir de duas dimensões: no sistema da retratística e no espaço urbano registrado fotograficamente. Cenários, mobiliário (de interiores e urbano) e especialmente o ferro ornamental são tratados como alguns dos suportes que organizam, na sociedade paulistana da virada do século XIX para o XX, as ações corporais e a delimitação dos espaços públicos e privados. Procura-se demonstrar em que medida as práticas cotidianas são determinadas por noções de decoro que se constituem materialmente, muitas vezes afasicamente e de modo diferenciado para os gêneros masculino e feminino.

Palavras-chave: cultura material; espaço público; fotografia; retratos; estudos de gênero; ornamentação.

\section{Abstract}

This paper discusses, based on two different parameters, the material culture applied to the development of men's and women's public image: based on 
portraiture systems and based on urban spaces photographically registered. Backdrops, furniture (for interiors and exteriors) and, in particular, ornamental iron objects are seen as some of the supports that arrange bodily actions and the development of public and private spaces boundaries in the city of São Paulo during the XIX to XX centuries transition. We try to demonstrate the amount of every day practices developed out of a (in many cases aphasiac and gender differentiated) sense of decorum materialistically formed.

Keyzwords: material culture; public space; photography; portraits; gender studies; ornamentation.

\section{Résumé}

Larticle analyse le rôle de la culture matérielle dans la construction de l'image publique des hommes et des femmes, en examinant deux dimensions: le système du portrait et celui de l'espace urbain enregistré photographiquement. Les scenarios, les meubles, le mobilier urbain et surtout les ferronneries sont traités comme des éléments qui organisent les actions du corps et la séparation entre les espaces publiques et privés dans la ville de São Paulo, au tournant du XIXe au XXe siècle. Larticle vise a démontrer comment les pratiques quotidiennes sont déterminées par des notions de bienséance qui sont établies à la fois matériellement et différemment pour les genres masculin et féminin. Mots-clés: culture matérielle; espace publique; photographie; portraits; études de genre; ornementation. 